REVISTA DE DERECHO UNED, núm. 5, 2009

\title{
EL PROCESO CONSENSUAL DE SEPARACIÓN Y DIVORCIO*
}

\author{
Sonia Calaza López \\ Profesora Titular acreditada de Derecho Procesal de la UNED
}

Resumen: Este trabajo analiza la virtualidad de la introducción de los procesos voluntarios de separación y divorcio en la futura Ley de Jurisdicción Voluntaria, así como el reconocimiento legal de la atribución de la disolución del vínculo matrimonial, a otros operadores jurídicos especialmente cualificados, distintos de los Jueces, como pudieran serlo los Notarios o los Secretarios Judiciales, a elección de los particulares.

Abstract: This paper analyzes the virtuality of the introduction of the voluntary processes of separation and divorce in the future Law of Voluntary Jurisdiction, as well as the legal recognition of the attribution of the dissolution of the marital bond to other legal operators specially qualified, different from the Judges, such as Notaries or Clerks of Court, as decided by the individuals.

Palabras clave: Procesos voluntarios de separación y divorcio. Disolución del vínculo matrimonial.

* Este trabajo constituye la síntesis de un capítulo de la monografía titulada "Los procesos matrimoniales. Nulidad, separación y divorcio», publicada recientemente en la Editorial Dykinson y elaborada en el marco de dos Proyectos de Investigación del Ministerio de Ciencia e Innovación, sobre las principales reformas procesales, pendientes de aprobación legislativa, con las referencias SEJ 2007-62039 y DER 2008-06460-C02-01, siendo el investigador principal del primero, el Prof. Vicente Gimeno Sendra (Catedrático de la Universidad Nacional de Educación a Distancia) y del segundo, el Prof. Antonio Fernández de Buján (Catedrático de la Universidad Autónoma de Madrid). 
Key words: Voluntary processes of separation and divorce. Dissolution of the marital bond.

Sumario: I. Introducción.-II. Petición de separación o divorcio.II.A. Cumplimiento de los requisitos temporales y materiales para el ejercicio de la acción.-II.B. Escrito de petición consensuada de separación o divorcio y documentos complementarios.-III. Ratificación de la solicitud de separación o divorcio.-IV. Práctica de la prueba y eventual intervención del Ministerio Fiscal.-V. Sentencia.VI. Recursos.-VII. Bibliografía.

\section{INTRODUCCIÓN}

El procedimiento de separación o divorcio consensual es aquél en el que no existe desavenencia, discordia, ni confrontación alguna entre los cónyuges, de suerte que ambos prestan su consentimiento para la constitución judicial de la separación o, en su caso, del divorcio ${ }^{1}$.

La nulidad matrimonial no podrá encauzarse, por elementales razones de interés general y de orden público, por el procedimiento consensual de disolución del vínculo conyugal, debiendo tramitarse, siempre y en todo caso, por el contencioso, y ello con independencia de la presencia o ausencia de conflicto, contradicción o disentimiento expreso entre las partes.

La imprescindible apreciación de la concurrencia de, al menos, una de las causas legalmente establecidas en el Código Civil para la admisión de la separación o del divorcio constituía, bajo la vigencia de la antigua Ley, una razón, tal vez suficiente, para que dicha decisión hubiere de ser, en exclusiva, jurisdiccional.

En el momento actual, la separación y el divorcio se configuran como legítimas opciones dependientes, en exclusiva, de la libre voluntad individual de los cónyuges, de suerte que la labor judicial, en ausencia de otras pretensiones complementarias de naturaleza no dispositiva, habrá de limitarse a decretar dicha separación o divorcio, sin la menor labor de interpretación, ni enjuiciamiento. Es por ello por lo que en esta materia, al igual que en algunas otras, dónde rigen

1 Vid., a propósito de la naturaleza no contenciosa de las peticiones de separación y divorcio presentadas de común acuerdo por ambos cónyuges o por uno con el consentimiento del otro, ENTRENA KLERR, C., Matrimonio, separación y divorcio, Ed. Aranzadi, Pamplona, 1982, pp. 581 y ss. 
intereses exclusivamente privados, entre personas bien avenidas, podrían descongestionarse de trabajo los Juzgados y derivar la verificación de dicha solicitud consensuada de separación o divorcio, a otros prestigiosos operadores jurídicos, como los Notarios o, en su caso, los Secretarios Judiciales ${ }^{2}$, a través de un procedimiento voluntario o, de utilizar la terminología de la futura Ley, de un expediente de jurisdicción voluntaria.

La libre opción de acudir, a elección de los particulares, implicados en este tipo de procesos, al Secretario Judicial o al Notario comportaría un menor coste económico y psicológico, además de suponer una mayor agilidad, sencillez y rapidez. Y todo ello, naturalmente, sin perjuicio de que, ante el surgimiento, presente o futuro, de una controversia entre las partes, pudieren éstas acudir a los Tribunales, para instar, a través de un proceso contencioso, dicha separación o divorcio, debido a la ausencia de plenitud de los efectos materiales de la cosa juzgada, característica de las resoluciones dimanantes de los procesos voluntarios.

La reconducción de los procesos consensuales, amistosos o voluntarios, dónde no confluyen, al propio tiempo, intereses sociales, dignos de una especial protección, por parte del Estado, a los trámites de la Jurisdicción Voluntaria ${ }^{3}$ ha sido, por lo demás, con alguna ma-

2 Vid., en este sentido, FERNÁNDEZ DE BUJÁN, A., quién afirma, con toda lógica, que «la separación y divorcio por mutuo consenso, podría asimismo formalizarse ante notario o secretario judicial, salvo la aprobación del convenio regulador, en los casos de existencia de menores de edad o incapacitados, que deberá ser aprobado por el Juez», en Hacia una teoría general de la Jurisdicción Voluntaria», volumen I, Ed. IUSTEL, Madrid, 2007, p. 218.

${ }^{3}$ Para un estudio pormenorizado y de conjunto sobre la Jurisdicción Voluntaria, se remite al lector a la obra de FERNÁNDEZ DE BUJÁN, A., A propósito de la competencia en materia de iurisdictio voluntaria en Derecho Romano, Revista de Derecho Notarial y A.A.M.N., T. XXVIII; Diferencias entre los actos de iurisdictio contenciosa y iurisdictio voluntaria en Derecho Romano, Estudios Homenaje a A. D`ors, vol. I, Pamplona, 1987; Consideraciones acerca del carácter clásico y jurisdiccional de la denominada por Marciano "Iurisdictio voluntaria, en D. 1.16.2. pr.», Estudios homenaje a J. Iglesias, Madrid, 1987; «Jurisdicción voluntaria en Derecho Romano», Madrid, 3. . ed., 1999; La jurisdicción voluntaria en la encrucijada: su conexión con el nuevo modelo procesal de la LEC del año 2000, Revista de Derecho y opinión, Córdoba, 2000; «Jurisdicción Voluntaria», Ed. Civitas, Madrid, 2001; Los principios informadores de la jurisdicción voluntaria: una propuesta de futuro, Anuario de Derecho de la U.A.M., vol. 5, 2001; "Consideraciones de lege ferenda en materia de jurisdicción voluntaria y Anteproyecto de Jurisdicción Voluntaria», Revista del Colegio de Abogados de Lugo, 2001 y 2002; Jurisdicción Voluntaria: naturaleza jurídica y diferencias de procedimiento con la jurisdicción contenciosa, Actualidad Civil, n. ${ }^{\circ} 36,2001$ y n. ${ }^{\circ} 37$; La jurisdicción voluntaria: racionalización y redistribución de competencias, Libro Homenaje a Sánchez Mera, Madrid, 2002; La Jurisdicción Voluntaria: una reforma legislativa pen- 
tización ${ }^{4}$, reclamado por amplios sectores de la doctrina ${ }^{5}$ y de la judicatura $^{6}$. Y es que si el proceso ha de colocarse siempre, tal y como

diente, Estudios Jurídicos. Ministerio de Justicia, vol. IV, 2002; Noción de iurisdictio y etapas. Jurisdicción contenciosa y jurisdicción voluntaria, Portal electrónico de Derecho, IUSTEL, 2002; La reforma legislativa de la jurisdicción voluntaria: reflexiones de presente y perspectivas de futuro, n. ${ }^{\circ}$ 163, 2004; Jurisdicción Voluntaria: Historia (I), Problemas (II), Interrogantes (III) y Soluciones (IV), Tribuna Pública, Mercados, Voz de Galicia, 12-9, 19-9, 26-9 y 3-10-2004; La reforma de la Jurisdicción Voluntaria: problemas, interrogantes, soluciones, Diario «La Ley» de 23 de marzo de 2005; El nuevo perfil de la Jurisdicción voluntaria en el Anteproyecto de Ley de octubre de 2005 (de tutela de relaciones jurídicas privadas a la protección de intereses generales, públicos o sociales), Diario La Ley de 8 de junio de 2006.; La Jurisdicción Voluntaria. El Anteproyecto de junio de 2006, en El Notario del siglo XXI, agosto de 2006; «Observaciones al Proyecto de Ley de Jurisdicción Voluntaria, de octubre de 2006 (I)», Diario La Ley de 27 de noviembre de 2006; Observaciones al Proyecto de Ley de Jurisdicción Voluntaria, de octubre de 2006 (y II), Diario La Ley de 28 de noviembre de 2006; El Notario como órgano de la Jurisdicción Voluntaria en el Proyecto de Ley de 20 de octubre de 2006, en El Notario del siglo XXI, 2006; La nueva configuración de la Jurisdicción Voluntaria en el Anteproyecto de Ley de junio de 2006, en «Otrosí. Revista del Colegio de Abogados de Madrid» n. ${ }^{\circ}$ 80, 2006; El Proyecto de Ley de Jurisdicción Voluntaria, en Economist\&Jurist n. ${ }^{\circ} 106$ y 107, 2007; La protección jurídica patrimonial de las personas con discapacidad, en libro compartido, dirección y coordinación Prof. I. Serrano, Ed. Tirant lo Blanch, Valencia, 2007; La Jurisdicción Voluntaria en el marco del Estado constitucional de Derecho, en Anales de la Academia Matritense del Notariado, 2007; La Jurisdicción Voluntaria en las Cortes Generales, Diario La Ley de 16 de octubre de 2007; Hacia una teoría general de la Jurisdicción Voluntaria», volumen I, Ed. IUSTEL, Madrid, 2007; Hacia una teoría general de la Jurisdicción Voluntaria, volumen II, Ed. IUSTEL, Madrid, 2008.

${ }^{4}$ Aún cuando, según MORENO CATENA, V., la ausencia de contradicción en el litigio ha dado lugar a un tratamiento procedimental asimilado a un acto de jurisdicción voluntaria, lo cierto es que la indisponibilidad del matrimonio exige la jurisdiccionalidad en el procedimiento y la inatacabilidad de la resolución, que pasa en autoridad de cosa juzgada, produciendo los mismos efectos que si hubiera recaído en el proceso contencioso, en Derecho Procesal Civil, parte especial, Ed. Colex, 3. ${ }^{\text {a }}$ ed., Madrid, 2003, p. 167.

5 Vid., PASTOR VITA, F. J., Una primera aproximación al Proyecto de Ley de reforma del Código Civil en materia de separación y divorcio, Diario La Ley n. ${ }^{\circ}$ 6235, 20 de abril de 2005, p. 2.; Vid., asimismo, ASENCIO MELLADO, J. M., cuando afirma que «se está, pues, ante un procedimiento asimilado a un acto de jurisdicción voluntaria, con normas específicas y apropiadas a su finalidad y fundamento», «Los procesos matrimoniales», en "Proceso Civil Práctico», Tomo IX-1, dirigido por GIMENO SENDRA, V., Ed. La Ley, Madrid, 2009, p. 4-187.

$6 \mathrm{Vid}$., FLORS MATÍES, J., cuando afirma que «si en lo concerniente a la separación o al divorcio no puede existir ya controversia entre las partes, ello significa que esa concreta materia ya no es objeto de un verdadero proceso (caracterizado por la contradicción), sino de un procedimiento de jurisdicción voluntaria al que, en su caso, puede acumularse un proceso, en sentido propio en lo que concierne a las pretensiones sobre medidas o efectos comunes derivados de la separación o el divorcio», Procedimiento, en Separación y divorcio tras la Ley 15/2005, VV.AA. (MONTERO AROCA, J.; FLORS MATÍES, J., ARENAS GARCÍA, R.), Ed. Tirant lo blanch, Valencia, 2006, p. 366. 
advirtieron los clásicos ${ }^{7}$, en la esfera del interés material, entonces no cabe ninguna duda al respecto de la necesaria celebración de los procesos materiales, por el cauce de los juicios voluntarios, caracterizados, entre otros atributos, por su gran flexibilidad, agilidad, transparencia y economía de medios materiales y humanos.

Aún es más, la fortaleza de la determinación de la voluntad individual de las personas a la hora de decretar la separación y el divorcio, unida a la visible ausencia de actuación jurisdiccional en esta actividad judicial ha impulsado, recientemente, a un destacado sector de nuestra procesalística ${ }^{8}$, a cuya toma de posición en esta cuestión nos adherimos, a opinar que tanto los procesos voluntarios como los contenciosos debieran reconducirse a los trámites de la Jurisdicción Voluntaria.

Ahora bien, la reconducción de los procesos de separación y divorcio, a los trámites de la Jurisdicción Voluntaria, no debiera hacerse, en cualquier caso, en materia de competencia, de manera indiscriminada. Y es que la presencia de pretensiones con un fuerte contenido dispositivo, como lo son, en la actualidad, la separación y el divorcio, a las que se accederá por la mera voluntad de al menos uno de los cónyuges, de manera conjunta a otras que son, a su vez, plenamente disponibles no debiera, a efectos de competencia, equipararse a las pretensiones contenciosas relativas a los hijos, dónde la disposición de los particulares es nula.

Así, pues, los procesos conformados por una conjunción de pretensiones dispositivas, dónde, a su vez, no hubiera conflicto inter partes debieran, a todas luces, dilucidarse ante fedatarios públicos especialmente prestigiados en nuestra Administración de Justicia, como lo son los Secretarios Judiciales y los Notarios, a elección de los particulares.

Sin embargo, aquellos procesos en los que, pese al contenido ampliamente dispositivo de la pretensión principal, que lo es la de la se-

${ }^{7}$ Vid., en este sentido, IHERING, R., La lucha por el Derecho, Ed. Termis, Colombia, 2000, p. 104.

$8 \mathrm{Vid}$., MONTERO AROCA, J., cuando afirma que «se trata de que para dictar esa resolución no se precisa la existencia de un verdadero proceso, bastando que en un expediente de jurisdicción voluntaria se constate la existencia de la voluntad de los dos cónyuges o incluso de la voluntad de uno de ellos, aparte del transcurso de un plazo de tres meses desde la celebración del matrimonio. Hoy la separación y el divorcio se decretan siempre por un juez pero este no actúa jurisdiccionalmente», en La modificación de los procesos matrimoniales, en Separación y divorcio tras la Ley 15/2005, VV.AA. (MONTERO AROCA, J.; FLORS MATÍES, J., ARENAS GARCÍA, R.), Ed. Tirant lo blanch, Valencia, 2006, p. 33. 
paración o el divorcio, se hubieren acumulado toda suerte de pretensiones, imperativas, unas, y dispositivas, otras, debieran ser objeto de exclusivo conocimiento judicial, pese a su tramitación por el cauce de la Jurisdicción Voluntaria, cuando no existiese conflicto latente entre las partes.

En este sentido, hemos de admitir que nuestra sobrecargada o, más bien, saturada justicia civil no debiera permitirse, ante la gran cantidad de procesos matrimoniales suscitados diariamente, en previsible aumento, ante los Juzgados y Tribunales españoles, la exclusividad de la Jurisdicción, en la declaración de la suspensión o, en su caso, de la disolución del vínculo conyugal, cuando los particulares se limitan a solicitar, ante los Tribunales de Justicia, la constatación, homologación, verificación o ejecución de su doble voluntad de disolver o extinguir su matrimonio.

La celebración de un proceso judicial, sin una dualidad real de partes enfrentadas constituye, en realidad, tal y como se ha afirmado ${ }^{9}$, una "ficción», en la que el Juez habrá de limitar su actividad a comprobar la existencia de unos concretos documentos.

La LEC contiene, en el momento actual, un proceso especial, original, individual y específico, en su artículo 777, para regular este peculiar proceso consensual de separación y divorcio.

\section{PETICIÓN DE SEPARACIÓN O DIVORCIO}

El precepto 81 del Código Civil, conforme a la redacción formulada por la Ley 15/2005, de 8 de julio, establece que «se decretará judicialmente la separación cualquiera que sea la forma de celebración del matrimonio: $1 .^{\circ}$ ) A petición de ambos cónyuges o de uno con el consentimiento del otro, una vez transcurridos tres meses desde la celebración de matrimonio. A la demanda se acompañará una propuesta de convenio regulador redactada conforme al artículo 90 de este Código. $2 .^{\circ}$ ) A petición de uno sólo de los cónyuges, una vez transcurridos tres meses desde la celebración del matrimonio. No será preciso el transcurso de este plazo para la interposición de la de-

9 Vid., en este sentido, PÉREZ GORDO, A., cuando afirma que "para ello no es necesario un Juez, ni crear una ficción del mismo, ni llevar a esos hombres de toga a actuar como simples funcionarios administrativos, ya que se les llega a privar de su plenitud jurisdiccional, convirtiéndoles en meros ejecutores de la voluntad de dos cónyuges», en Los juicios matrimoniales (nulidad, separación y divorcio), Bosch, Barcelona, 1982, pp. 183 y 184. 
manda cuando se acredite la existencia de un riesgo para la vida, la integridad física, la libertad, la integridad moral o libertad e indemnidad sexual del cónyuge demandante o de los hijos de ambos o de cualquiera de los miembros del matrimonio. A la demanda se acompañará propuesta fundada de las medidas que hayan de regular los efectos derivados de la separación».

Aún cuando el precepto recién señalado se refiere a la petición o solicitud de la separación, ante el Juez, con la descripción de una pormenorizada casuística — «a petición de ambos cónyuges», «a petición de uno con el consentimiento del otro» y, al fin, «a petición de uno sólo de los cónyuges»- lo cierto es que los efectos derivados de la solicitud de separación no varían, como veremos, en función de la procedencia subjetiva, en el caso concreto, de la petición efectuada.

Los dos primeros supuestos vienen referidos a la petición de separación consensual — «a petición de ambos cónyuges» y «a petición de uno con el consentimiento del otro»-, en tanto el tercero parece aludir a la solicitud de separación contradictoria — «a petición de uno sólo de los cónyuges»-. En ninguno de los tres casos recién expuestos, el cónyuge promotor de la solicitud de separación o, caso de ser una petición dual, los cónyuges, habrán de alegar motivos, razones o causas de la separación, limitándose a solicitarla, ante el Juez competente.

Una vez cursada la solicitud de separación, el Juez habrá de limitarse a verificar la concurrencia de los requisitos objetivos establecidos en la norma, como lo son el transcurso de los tres meses desde la celebración del matrimonio y la presentación del convenio regulador, no pudiendo, de ninguna manera, descender al análisis de otras razones de índole moral, ética o espiritual, que puedan obstaculizar o, de cualquier modo, ralentizar la petición propuesta por las partes.

Esta imposibilidad del Juez, de entrar a valorar la conveniencia o inconveniencia de la separación, conforme a parámetros distintos a la libre voluntad de, al menos, uno de los cónyuges, ha impulsado, a la doctrina $^{10}$, a opinar que la actuación del Juez, en las separaciones y divorcios de mutuo acuerdo, no ha de identificarse tanto con una aprobación, como, en puridad, con una «homologación judicial» ${ }^{11}$.

${ }^{10}$ LASARTE, C., Principios de Derecho Civil VI, Derecho de familia, Ed. Marcial

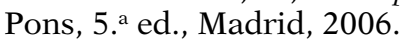

${ }_{11}$ Vid., MONTERO AROCA, J., cuando advierte que «el procedimiento del artículo 777, como hemos dicho reiteradamente, no es un proceso, sino un expediente de jurisdicción voluntaria, y en lo que se refiere a la separación misma el juez no tiene más 
El artículo 86 del Código Civil establece, de conformidad con la nueva redacción otorgada por la Ley 15/2005, de 8 de julio, que «se decretará judicialmente el divorcio, cualquiera que sea la forma de celebración del matrimonio, a petición de uno sólo de los cónyuges, de ambos o de uno con el consentimiento del otro, cuando concurran los requisitos y circunstancias exigidos en el artículo $81 »$.

\section{II.A. Cumplimiento de los requisitos temporales y materiales para el ejercicio de la acción}

El necesario agotamiento del transcurso del plazo de tres meses desde la celebración del matrimonio para la interposición de la petición consensual o demanda contenciosa constituye, al igual que acontecía con la regulación derogada, un obstáculo a la tutela judicial efectiva y una dilación indebida ${ }^{12}$. Y es que si la nueva Ley aboga por un proceso matrimonial dónde prime la autonomía de la voluntad, la libertad individual y el libre desarrollo de la personalidad, entonces esta filosofía del proceso, en el que se dilucidan las desavenencias surgidas en el seno del matrimonio, no parece acorde con la nueva imposición de un plazo, por breve que sea, para la interposición de la demanda.

En este sentido, la interposición de la petición o demanda debiera quedar exenta de toda suerte de condicionantes, bien sean temporales, bien lo sean causales. En relación con los primeros, ya hemos tenido ocasión de advertir, en estudios anteriores a éste, —dónde, por cierto, manifestamos reflexiones, ideas y posiciones muy próximas a la reforma operada con posterioridad ${ }^{13}$-, que el mero transcurso

función que controlar tanto la voluntariedad del consentimiento como el plazo. Cumplidos esos requisitos, el juez no aprueba la separación sino que simplemente la homologa, y a este efecto debe tenerse en cuenta que si en la homologación el juez se limita a constatar la concurrencia de los requisitos normalmente formales previstos en la ley sin que tome decisión alguna (como ocurre en la transacción del art. 19.2 de la LEC respecto de los derechos disponibles), en la aprobación el juez debe decidir si lo propuesto por las partes es lo más adecuado teniendo en cuenta un interés superior a las propias partes (caso de la aprobación del convenio regulador en la parte relativa a los hijos menores o incapacitados)», La modificación de los procesos matrimoniales, en Separación y divorcio tras la Ley 15/2005, VV.AA. (MONTERO AROCA, J.; FLORS MATÍES, J., ARENAS GARCÍA, R.), Ed. Tirant lo blanch, Valencia, 2006, p. 73.

12 Para un estudio pormenorizado sobre esta cuestión, se remite al lector, al trabajo de GIMENO SENDRA, V., El derecho a un proceso sin dilaciones indebidas, Jornadas sobre Derechos Humanos, Poder Judicial, número especial, CGPJ, Madrid, 1986.

${ }^{13}$ Vid., en este sentido, CALAZA LÓPEZ, S., dónde ya advertí que «no cabe duda que el transcurso del tiempo constituye un hecho jurídico que, como tal, influye tanto en el nacimiento de los derechos, a través de la usucapión, como en su extinción, 
del tiempo, lejos de promover una avenencia, entre las partes, puede potenciar, incluso, el antagonismo, la conflictividad y hasta la agresividad de la ya deteriorada relación matrimonial.

Aún cuando el transcurso del plazo legalmente establecido no resulta, en línea de principio, excesivamente costoso, a nivel personal, debido a la brevedad en tiempo real de sus tres meses de duración - pese a la «lentitud temporal psicológica» característica del transcurso de todos los plazos procesales y, especialmente, de los que inciden, de una manera más directa, en el plano íntimo de las personas- lo cierto es que no resulta coherente con el sistema actual la imposición de este peculiar plazo procesal. Y ello especialmente en los procesos voluntarios de separación divorcio, dónde se perciben, con extraordinaria rapidez, desde el propio momento de celebración del matrimonio, las razones, motivos o causas de ruptura provisional o definitiva de la relación matrimonial.

La petición consensuada de separación o divorcio, en los tres primeros meses de convivencia matrimonial, constituye, desde luego, una civilizada forma de operar, ante los Tribunales de Justicia, que, por lo demás resulta muy próxima a la demanda de nulidad por «error en aquellas cualidades personales que, por su entidad, hubieren sido determinantes de la prestación del consentimiento».

Y es que la revelación, durante los tres primeros meses de convivencia, de la ausencia, unilateral o recíproca, de cualidades esenciales, determinantes, incluso, de una «incompatibilidad», con el cónyuge, con el que se ha contraído, tan recientemente, matrimonio, supone, a todas luces, un «inconveniente» de muy difícil regresión.

La imposición de obstáculos procesales como el obligatorio transcurso de plazos temporales que, no obstante su brevedad, supongan, en definitiva, una injustificada dilación en el ejercicio del derecho de acción no conlleva ventaja alguna.

En este sentido, hemos de advertir que, pese a la encomiable reducción del plazo, operada por la Ley vigente, no nos resulta tan

por la caducidad o la prescripción extintiva, también en la adquisición de capacidad por la mayoría de edad o de la nacionalidad por residencia o por posesión de estado, pero la exigencia de un plazo mínimo para acudir a los tribunales ejercitando una acción es insólito. Fuera de los casos de nombramiento de representante al desaparecido, declaración de ausencia o fallecimiento, cuya prolongación en el tiempo al objeto de futura declaración resulta lógica, no se contemplan otros casos en nuestro ordenamiento», en La justificación de los plazos procesales en las causas de divorcio, Iuris n. ${ }^{\circ} 82$, Madrid, abril, 2004, p. 31. 
cuestionable la extensión del plazo, que, ciertamente, ha mejorado, merced a su escasa duración, como su propia existencia.

La nueva Ley 15/2005 ha abandonado el clásico espíritu tuitivo, protector y, en definitiva, intervencionista, del Estado, en un plano tan íntimo para las personas, como lo es su opción matrimonial. Todas las razones, motivos y causas que provocan la «ruptura» transitoria o definitiva de la pareja, no trascienden, no se publicitan, no se pregonan, ante los Tribunales de Justicia, quedando, afortunadamente, en el plano íntimo.

Ante estas evidenciables novedades, no se comprende la imposición del plazo procesal para el ejercicio de la acción, en ningún caso, y de manera muy destacada, insistimos, en la voluntaria, consensual o amistosa, dónde la solicitud de tutela judicial, responde antes a una petición de supervisión, homologación o control de la legalidad, como pronto expondremos, que a una demanda de «enjuiciamiento», en sentido estricto.

En relación con la imposición de requisitos, criterios, motivos o causas objetivas, para la interposición de la demanda, en los procesos matrimoniales, también hemos tenido ocasión de pronunciarnos ${ }^{14}$, por lo que basta reiterar, en este momento, nuestra posición contraria a la imposición de trabas materiales al ejercicio de la acción.

La Ley 15/2005 ha establecido, en este sentido, una serie de excepciones, al imperativo cumplimiento del plazo de tres meses, para la interposición de la pretensión matrimonial. Así, pues, el precepto $81.2^{\circ}$.II establece que "no será preciso el transcurso de este plazo para la interposición de la demanda cuando se acredite la existencia de un riesgo para la vida, la integridad física, la libertad, la integridad moral o religiosa e indemnidad sexual del cónyuge demandante o de los hijos de ambos o de cualquiera de los miembros del matrimonio».

${ }^{14} \mathrm{Vid}$., CALAZA LÓPEZ, S., cuando afirmé, bajo la vigencia de la Ley que «la concepción de la separación y del divorcio, en materia de regulación legal, no debiera responder a la premisa de una conceptualización de dicha posibilidad, consistente en una nueva forma de vida como un fracaso matrimonial culposo o doloso, como si de un tipo penal se tratase, en el que uno de los cónyuges o ambos deban probar fehacientemente la existencia de unas causas - así, por ejemplo, malos tratos, atentado contra la vida, adulterio, incumplimiento de los deberes conyugales, entre otras- por las que tienen derecho a separarse y divorciarse, por contraposición a la inexistencia de dicho derecho ante la total ausencia de unas causas que lo justifiquen o, en su defecto, al transcurso de un plazo temporal fijado en atención a criterios que no responden a las reglas de la lógica», en La justificación de los plazos procesales en las causas de divorcio, Iuris n. ${ }^{\circ} 82$, Madrid, abril, 2004, p. 35. 
Esta enumeración de motivos que eximen del plazo temporal ha sido criticada, entre algún sector de la abogacía ${ }^{15}$, toda vez que la Ley no debiera, bajo su punto de vista, entremezclar conceptos e implicar un aspecto puramente objetivo con la lacra social que supone el maltrato en nuestros días.

La gravedad de las causas enumeradas en la Ley 15/2005, bien merece, bajo nuestro punto de vista, sin embargo, constituir una excepción al transcurso del plazo de tres meses para la interposición de la demanda, toda vez que ello supondrá, al menos, la agilización de un proceso judicial que resulta, a todas luces, en tales supuestos, además de conflictivo y desapacible, esencialmente traumático.

La alusión a la concurrencia, en el seno de la institución matrimonial, de los «malos tratos» recién transcritos, en la regulación de la separación y el divorcio, permite, por lo demás, una imprescindible compatibilidad entre dos Leyes ${ }^{16}$, la del divorcio, por un lado, y la Ley integral contra la Violencia de género, por el otro, destinadas, en un número de casos nada desdeñable, a conformar los fundamentos jurídicos de las sentencias que hallan de pronunciarse sobre los tipos de pedimentos propios de tales procesos.

La inmensa mayoría de demandas de nulidad, separación y divorcio no presentan, es de prever y, sobre todo, de esperar, indicios o evidencias de malos tratos, si bien ello no ha de resultar óbice, sino a

15 Vid., en este sentido, CAÑETE QUESADA, A., quién, al propio tiempo, afirma que «si la reforma aboga por evitar la conflictividad que en sí misma encierran los procesos familiares, resulta curioso que para poder separarse o divorciarse antes de los tres meses desde la celebración del matrimonio haya que acudir, argumentar o esgrimir dicho conflicto a los únicos fines de excusar un simple requisito procesal», en El anteproyecto de Ley por el que se modifica el Código Civil en materia de separación y divorcio, Diario La Ley n. ${ }^{\circ} 6140,2$ de diciembre de 2004, p. 3.

16 Esta compatibilidad ha sido, por lo demás, reclamada por SAN SEGUNDO MANUEL, T., cuando, antes de la vigencia de la Ley 15/2005, formuló los siguientes interrogantes: "¿ cómo podrá evitarse la violencia si, de los procesos de separación y divorcio, desaparecen las causas legitimotes de ambas instituciones jurídicas siendo, a estos litigios, a los que acuden en primer término las víctimas afectadas por la violencia de género? Y ¿ cómo podrá trasladarse a los juzgados que apliquen la Ley de Violencia de Género cuando se revele causa para ello en los juzgados en que se tramita l separación o el divorcio si, por otra parte, la reforma proyectada del divorcio impide cualquier alusión distinta de la expresión escuetamente voluntarista del insto el divorcio, solicito la separación, o pido la nulidad de mi matrimonio?», en Maltrato y Ley de divorcio, en «Familia, matrimonio y divorcio en los albores del siglo XXI», Jornadas internacionales sobre las reformas de Derecho de Familia, bajo la dirección de LASARTE, C., Ed. IDADFE, UNED y El Derecho, Madrid, 2006, p. 337. 
riesgo de incurrir en una incoherencia legislativa ${ }^{17}$, para que quiénes hayan sido víctimas, en su relación matrimonial, de aquellos episodios violentos, deban ponerlo en conocimiento del Juez, en su escrito de demanda, al objeto de que éste proceda, con carácter urgente, y sin perjuicio de la realización de las restantes actuaciones que considere pertinentes, al efecto, a la inmediata disolución del vínculo. La actual inexistencia de causas no entorpece, obstaculiza, ni impide el reconocimiento, la procedencia e, incluso, la conveniencia de la alegación de éstas, en aquellos casos especialmente dramáticos en los que los particulares precisen una tutela judicial más rápida y efectiva.

Sin perjuicio de lo anterior, resulta claro que los problemas de competencia que eventualmente se suscitasen, en estos casos, entre los Juzgados de Violencia sobre la mujer y los Juzgados civiles podrían demorar inútilmente el conocimiento de la concreta pretensión de divorcio o, tal y como se ha advertido ${ }^{18}$, consumir un tiempo excesivo, haciendo más aconsejable para la propia maltratada dejar transcurrir esos tres meses y acudir a la jurisdicción civil para lograr una respuesta judicial más rápida.

Ahora bien, nuestra toma de posición, favorable a la exención del cumplimiento del requisito temporal, ante la evidencia o hipótesis de tales riesgos, no conlleva que nos resulte, al propio tiempo, encomiable la regulación vigente, toda vez que la exigencia de un plazo, así como la casuística enumeración de excepciones a dicho pla-

$17 \mathrm{Y}$ es que la ausencia de causas, ha impulsado a algunos autores, a estimar que existe una incoherencia o incompatibilidad entre la LO 1/2004, de 28 de diciembre, de Medidas de Protección Integral contra la Violencia de Género y la Ley 15/2005, de 8 de julio, por la que se modifican el CCiv y la LEC en materia de separación y divorcio. Vid., en este sentido, entre otros, UREÑA MARTÍNEZ, M., cuando señala que «del análisis conjunto de ambas leyes se observa que el legislador en tan breve plazo de tiempo - seis meses - ha dado distintas respuestas jurídicas al problema de los conflictos familiares. La LO 1/2004 criminaliza cualquier acto de violencia como consecuencia de una relación de poder o superioridad del varón contra la mujer que mantiene o ha mantenido una relación matrimonial o de afectividad por leve que sea, aun sin convivencia, ya que el legislador considera la violencia de género como un problema social y no de ámbito privado; de ahí que insista en la idea de denuncia de esa lacra social. Por el contrario, la Ley 15/2005 se decanta por silenciar las causas generadoras del conflicto familiar - vgr., los malos tratos- en lo concerniente a la separación matrimonial; fundamentando su posición con el argumento de que la alegación de las causas de la separación origina una mayor conflictividad entre los cónyuges y entre ellos y sus hijos», en Separación conyugal y malos tratos, Aranzadi Civil 6/2007, BIB 2007/118, p. 13.

18 Vid., al respecto, PASTOR VITA, F. J., Una primera aproximación al Proyecto de Ley de reforma del Código Civil en materia de separación y divorcio, Diario La Ley n. ${ }^{\circ}$ 6235, 20 de abril de 2005, p. 5. 
zo supone, así nos lo parece, una tímida regresión hacia el sistema causal.

Las demandas matrimoniales no debieran quedan al albur de requisitos materiales ni temporales de ninguna clase, bastando, como, por lo demás acontece en la generalidad de procesos civiles, la concurrencia de los presupuestos procesales inherentes a todo proceso judicial.

La creación de Oficinas de Señalamiento Inmediato permitirá tramitar, con la debida celeridad, las demandas consensuales de separación y divorcio. La Ley se refiere también a las demandas consensuales de nulidad, al efecto de su presentación ante estas oficinas, si bien, tal y como ya se ha advertido ${ }^{19}$, este tipo de demandas no debieran haberse incluido debido a que carecen, por su propia esencia, del atributo de la concordia, ausencia de conflicto, ni consentimiento recíproco entre los cónyuges.

\section{II.B. Escrito de petición consensuada de separación o divorcio y documentos complementarios.}

Las peticiones de separación o divorcio presentadas de común acuerdo por ambos cónyuges o por uno con el consentimiento del otro se tramitarán por el procedimiento establecido en el artículo 777 de la LEC.

Conviene resaltar, en este momento, que la LEC denomina "petición» - y no «demanda»-, pese a constituir el punto de partida de un proceso judicial, a la solicitud consensual de separación y divorcio, lo cual nos parece acertado si tomamos en consideración la conveniencia de que dicha materia se traslade a la futura Ley de Jurisdicción Voluntaria, dónde debiera conferirse capacidad de resolución, de este tipo de concordias, que no discordias, jurídicas, no sólo a los Jueces, sino también a otros operadores especialmente cualificados, como lo serían los Notarios y Secretarios Judiciales, ambos fedatarios de la legalidad, en sus respectivos ámbitos de la función pública.

Aún cuando la LEC se refiera, con notable acierto, a este escrito de solicitud consensual de separación o divorcio, como «petición» y no como "demanda», lo cierto es que ha de contener, ello no obstante, todos los extremos legalmente exigibles a aquélla.

19 Vid., CASTELLÓ GARCÍA, G., Juicios rápidos en el proceso civil, Actualidad Jurídica Aranzadi n. ${ }^{\circ}$ 699/2006, BIB 2006/77, p. 2. 
La petición de separación o divorcio ha de resultar, como es lógico, suficientemente ilustrativa, al menos, de la concreta pretensión propuesta, de la posible existencia de hijos comunes, así como de las circunstancias personales y patrimoniales en que se encuentren los cónyuges. A esta petición habrán de acompañarse, asimismo, todos los documentos públicos acreditativos, tanto del matrimonio, como, en su caso, del nacimiento de los hijos, el convenio regulador y, en su caso, el acuerdo alcanzado gracias a la mediación familiar.

La plausible instauración de un proceso matrimonial, amparado en la primacía de la voluntad de los cónyuges, permite que en esta solicitud consensuada - al igual que acontecía, por lo demás, con la demanda contenciosa de separación o divorcio- no deban concretarse, ni mucho menos, en un momento ulterior, probarse las de causas, motivos o razones que han dado lugar a la ruptura conyugal.

La propia Exposición de Motivos de la Ley 15/2005 explicita, en este sentido, que esta Ley, de acuerdo con los valores y principios constitucionales que inspiran la institución matrimonial, persigue ampliar el ámbito de libertad de los cónyuges en lo relativo al ejercicio de la facultad de solicitar su disolución. Con este propósito, se estima que el respeto al libre desarrollo de la personalidad, garantizado por el artículo $10.1^{\circ}$ de la CE, justifica reconocer mayor trascendencia a la voluntad de la persona cuando ésta ya no desea seguir vinculada con su cónyuge. Así, el ejercicio de su derecho a no continuar casado no puede hacerse depender de la demostración de la concurrencia de causa alguna, pues la causa determinante no es más que el fin de esa voluntad expresada en su solicitud, ni, desde luego, de una previa e ineludible situación de separación.

Conviene, asimismo, precisar que si respecto de la demanda contenciosa de separación y divorcio cabría esperar, pese a la nueva regulación procesal matrimonial, que una de las partes, en concreto, el actor, adjuntase una argumentación ilustrativa de las razones que han provocado su motivación favorable a la suspensión o disolución del vínculo conyugal, al objeto de apoyar en dichos argumentos las pretensiones personales y patrimoniales acumuladas a la propia pretensión de separación o divorcio, en la solicitud consensual no se producirá, a buen seguro, dicha impropia alusión a las causas íntimas que provocaron la crisis, toda vez que ambas partes estarán interesadas en la aprobación de un convenio que han alcanzado conjuntamente.

$\mathrm{Al}$ escrito por el que se promueva el procedimiento, según dispone el segundo apartado del artículo 777, conforme a la nueva redac- 
ción otorgada por la Ley 15/2005 deberá acompañarse la certificación de la inscripción del matrimonio y, en su caso, las de inscripción de nacimiento de los hijos en el Registro Civil, así como la propuesta de convenio regulador conforme a lo establecido en la legislación civil y el documento o documentos en que el cónyuge o cónyuges funden su derecho, incluyendo, en su caso, el acuerdo final alcanzado en el procedimiento de mediación familiar. Si algún hecho relevante no pudiera ser probado mediante documentos, en el mismo escrito se propondrá la prueba de que los cónyuges quieran valerse para acreditarla.

Además de estos documentos materiales, el actor también habrá de aportar, como es lógico, los documentos procesales exigibles en todo tipo de procesos civiles, como lo son el poder notarial o apud acta conferido al procurador y aquellos otros que resulten acreditativos de la competencia judicial.

En el proceso matrimonial, ya sea contencioso, ya sea consensual, a diferencia de lo que acontece en la generalidad de procesos civiles presididos por el principio dispositivo, la admisión de los hechos por las partes no comporta la automática fijación de los mismos, con la consiguiente elusión de la práctica de la prueba, que habrá de acordarse, incluso de oficio, cuando las circunstancias concurrentes en el caso concreto así lo aconsejen.

Así, pues, los peticionarios habrán de adjuntar a su solicitud voluntaria de separación o divorcio cuántos documentos apoyen, no ya esta pretensión principal, que, como es sabido, no precisa acreditación material alguna -más allá de la documental de la inscripción matrimonial, al efecto del referido transcurso del plazo de tres meses- sino las medidas de orden o naturaleza personal, familiar y patrimonial que hubieren sido acordadas en el convenio.

La solicitud consensual de separación o divorcio habrá de contener, de manera conjunta a la petición de suspensión o disolución del vínculo conyugal, como presupuesto de su admisibilidad ${ }^{20}$, la de medidas relativas a la aprobación de los efectos personales y patrimoniales propuestos en el convenio, debiendo distinguirse, a estos

${ }^{20} \mathrm{Vid}$., en este sentido, GONZÁLEZ DEL POZO, J. P., cuando advierte que «la propuesta de convenio regulador es un presupuesto de admisibilidad de la demanda de separación o divorcio consensuales", Los procedimientos consensuales, en VV.AA. (GONZÁLEZ DEL POZO, J. P., PLANES MORENO, M. D. y SANTANA PÁEZ, E.), Los procesos de familia: una visión judicial. Compendio práctico de doctrina y jurisprudencia sobre los procesos de familia y menores, coordinados por HIJAS FERNÁNDEZ, E., Ed. Colex, Madrid, 2007, p. 531. 
efectos, de un lado, las medidas entera o plenamente dispositivas y, de otro, las sustraídas a la libertad de actuación de las partes.

En la solicitud habrán de constar, pues, de manera clara, precisa, ordenada y diferenciada la conjunción de todas estas peticiones o solicitudes dispositivas con la de las pretensiones relativas a relaciones jurídico-materiales regidas por normas de derecho imperativo, toda vez que entre tanto las primeras habrán de regirse, con carácter habitual, por las disposiciones comunes a la generalidad de procesos civiles, respecto de las segundas se predicarán todas las especialidades en materia de alegaciones y prueba a las que nos hemos referido en el capítulo precedente.

Asimismo, dentro de las peticiones y pretensiones dispositivas, todavía cabe establecer una nítida distinción entre las principales, que se refieren a la solicitud de separación y divorcio, respecto de las cuales ha de destacarse que el Juez queda, sin más, vinculado por dicha solicitud, y las relativas a los bienes económicos o patrimoniales de los cónyuges, que habrán de ser objeto, sin embargo, de verdadero enjuiciamiento.

La notable divergencia existente entre las peticiones y pretensiones que conforman, en unidad de alegación, el escrito inicial del proceso consensual de separación y divorcio permitirá, al Letrado, destinar una mayor dedicación a la narración de los hechos, así como a la incorporación de documentos complementarios e, incluso, a la aportación de argumentos jurídicos, de unas pretensiones, frente a la mera descripción de las restantes solicitudes, para el éxito de todas ellas.

El convenio regulador habrá de referirse, al menos, según el precepto 90 del Código Civil, a los siguientes extremos: $1 .^{\circ}$ ) el cuidado de los hijos sujetos a la patria potestad de ambos, el ejercicio de ésta y, en su caso, el régimen de comunicación y estancia de los hijos con el progenitor que no viva habitualmente con ellos; $2^{\circ}$ ) si se considera necesario, conforme a la introducción operada por Ley 42/2003, de 21 de noviembre, el régimen de visitas y comunicación de los nietos con sus abuelos, teniendo en cuenta, siempre, el interés de aquéllos; $3^{\circ}$ ) la atribución del uso de la vivienda y ajuar familiar; $4 .^{\circ}$ ) la contribución a las cargas del matrimonio y alimentos, así como sus bases de actualización y garantías en su caso; $5^{\circ}$ ) la liquidación, cuando proceda, del régimen económico del matrimonio; $6^{\circ}{ }^{\circ}$ la pensión que, conforme al artículo 97, correspondiese satisfacer, en su caso, a uno de los cónyuges.

La ausencia de presentación del convenio regulador, de manera conjunta a la interposición, ante el Juez competente, de la solicitud 
consensuada de separación o divorcio conlleva su automática inadmisión, sin que sea posible su subsanación, puesto que la existencia de este convenio, tal y como se ha advertido ${ }^{21}$, constituye la esencia misma de la petición de suspensión o disolución conyugal común acuerdo.

Los acuerdos de los cónyuges, adoptados para regular las consecuencias de la nulidad, separación o divorcio serán aprobados por el Juez, salvo si son dañosos para los hijos o gravemente perjudiciales para uno de los cónyuges. La denegación habrá de hacerse mediante resolución motivada y en este caso los cónyuges deben someter a consideración del juez nueva propuesta para su aprobación, si procede. Desde la aprobación judicial, podrán hacerse efectivos por a vía de apremio (ex. art. 90. II del CCiv.).

La labor judicial en materia de pactos, convenios o acuerdos conyugales, tal y como puede fácilmente colegirse de la redacción del precepto recién trascrito, no es, en puridad, de enjuiciamiento, sino de mera vigilancia, supervisión y control de la legalidad. En este sentido, tanto el acuerdo inicialmente propuesto, como el sobrevenido, como consecuencia de una negativa motivada a la aprobación de aquél otro, procederán, en exclusiva, de los cónyuges, quedando limitada, la función del Juez a verificar el equilibrio económico alcanzado en dichos acuerdos y, en su caso, a impedir que uno de los cónyuges o los hijos queden en una situación gravemente perjudicial respecto del otro cónyuge.

Las medidas que el juez adopte en defecto de acuerdo, o las convenidas por los cónyuges, podrán ser modificadas judicialmente o por nuevo convenio cuando se alteren sustancialmente las circunstancias (ex. art. 90. III del Código Civ.).

La eventual modificación de las circunstancias económicas concurrentes en el momento de adopción del convenio o, en su defecto, de las medidas judicialmente decretadas, como pudieran serlo, entre otras, la pérdida del puesto de trabajo de uno de los cónyuges, conllevarán, como es lógico, la posibilidad de someter, al Juez, un nuevo acuerdo para su aprobación o, en su caso, de solicitar unas nuevas medidas, más ajustadas a la mutación fáctica acontecida en el momento actual, en virtud del límite temporal de la cosa juzgada material.

${ }^{21} \mathrm{Vid}$., en este sentido, FLORS MATÍES, J., El actual procedimiento consensual para la separación y el divorcio, en Separación y divorcio tras la Ley 15/2005, de VV.AA. (MONTERO AROCA, J.; FLORS MATÍES, J., ARENAS GARCÍA, R.), Ed. Tirant lo blanch, Valencia, 2006, p. 515. 


\section{RATIFICACIÓN DE LA SOLICITUD DE SEPARACIÓN O DIVORCIO}

El artículo $777.3^{\circ}$ de la LEC establece que «a la vista de la solicitud de separación o divorcio, se mandará citar a los cónyuges, dentro de los tres días siguientes, para que ratifiquen por separado su petición. Si ésta no fuera ratificada por alguno de los cónyuges, se acordará de inmediato el archivo de las actuaciones, sin ulterior recurso, quedando a salvo el derecho de los cónyuges a promover la separación o divorcio conforme a lo dispuesto en el artículo 770».

La exigencia legal expresa de la ratificación en unidad de acto y por separado de la petición, en lugar de conferir, a los particulares, en principio, bien avenidos, la posibilidad de ratificación individual de uno, con el consentimiento del otro, a expensas de una ulterior ratificación, responde, probablemente, a la necesidad de evitar los vicios que se producían bajo la vigencia de la Ley 30/1981, dónde era frecuente, según nos informan quiénes visualizaban la praxis cotidiana de este tipo de procesos ${ }^{22}$, la utilización abusiva de esta práctica para dilatar el proceso contencioso.

$\mathrm{Y}$ es que evidentes razones de celeridad, agilidad y economía procesal, de un lado, así como de seguridad jurídica, de otro, abogan por esta imprescindible ratificación conjunta de la solicitud consensual de separación y divorcio, toda vez que, ante la más mínima quiebra de la voluntad, atinente a cualquier extremo personal o patrimonial relacionado con la separación o divorcio - que no con la propia petición de tales métodos de disolución del vínculo o, en su caso, de la convivencia conyugal, frente a la que no cabe, en la actualidad, posibilidad de oposición alguna-, queda expedita la vía contenciosa, dónde podrán ventilarse, con la debida fluidez, aquellas divergencias.

El imperativo cumplimiento, por razones de seguridad jurídica, de la ratificación separada, que reside, fundamentalmente, en la primacía de la libertad, espontaneidad, individualidad y responsabilidad a la hora de afrontar una solución unívoca al proceso consensuado, carece de virtualidad, tal y como se ha afirmado $^{23}$, en el actual siste-

${ }^{22} \mathrm{Vid}$., esta reflexión, si bien referida, en el marco del derogado proceso contencioso, al "escrito de solicitud de cambio de procedimiento», VILALTA, A. E. y MÉNDEZ, R. M., Divorcio contencioso, Ed. Bosch, Barcelona, 1998, p. 15.

${ }^{23} \mathrm{Vid}$., en sentido crítico, GONZÁLEZ DEL POZO, J. P., cuando advierte que «la razón de ser de la ratificación separada se proyecta, fundamentalmente, sobre el convenio regulador, y, ciertamente, no se alcanza a ver qué tipo de intimidación, presión o influencia de un cónyuge sobre otro se quiere evitar con la ratificación sepa- 
ma no causal, respecto de la pretensión principal de separación o divorcio, quedando, por tanto, su finalidad residenciada en la obtención separada de la conformidad reinante, entre ambos cónyuges, respecto de las medidas adoptadas en el convenio.

La ratificación de la solicitud de separación y divorcio, así como del convenio regulador constituye, según ha expresado la jurisprudencia ${ }^{24}$, un acto solemne que ha de realizarse por los cónyuges -que, en todo caso, ya han debido suscribir el convenio previamente pactado- en presencia judicial y por separado, en el que queda plenamente garantizado que tal ratificación y el consentimiento se prestan de forma libre, voluntaria y consciente, puesto que inmediatamente genera efectos jurídicos irrevocables.

Tanto es así que el eventual cambio de parecer, manifestado por uno de los cónyuges, en un momento posterior al de la ratificación, ya sea debido a una libre, consciente y espontánea modificación de la voluntad inicialmente prestada, ya incluso por la eventual apreciación de un vicio en aquél consentimiento carece de toda eficacia, toda vez que el fundamento de la ratificación reside, según constante jurisprudencia ${ }^{25}$, en la constitución de una situación jurídica irreversible.

rada del mismo cuando el convenio no deja de ser un negocio jurídico típico del derecho de familia, más completo si se quiere que unas capitulaciones matrimoniales, pero no de mayor importancia que éstas o cualquier otro contrato entre cónyuges, que éstos pueden celebrar libremente, en documento público o privado, sin limitación o cortapisa alguna encaminada a garantizar la plena libertad de cada uno de ellos en el momento de prestar el consentimiento", Los procedimientos consensuales, cit., 2007, p. 568 .

${ }^{24}$ Vid., con cita de una abundante jurisprudencia, la AAP de Barcelona, de 30 de septiembre de 2002, r. 21779.

25 Vid., entre otras, la SAP de Alicante, de 18 de octubre de 2001 y el AAP de Ciudad Real, de 21 de mayo de 2004. Vid., asimismo, la clarificadora SAP de Barcelona, de 3 de diciembre de 1999, dónde se afirma que «la Disposición Adicional 6. ${ }^{\mathrm{a}}$ la Ley 30/1981, de 7 de julio (...) prevé, en garantía del ciudadano, que la solicitud inicial sobre separación matrimonial sea ratificada personalmente por cada uno de los cónyuges por separado y en presencia judicial. La pretensión contenida en la demanda, ratificada en la forma prevista en la ley, constituye un acto propio que no admite la validez de una ulterior declaración de voluntad en sentido contrario, por las exigencias del principio de seguridad jurídica consagrado en el art. 9 de la Constitución, como derecho fundamental, y por la eficacia de las declaraciones de voluntad recepticias derivada del art. 1255 del Código Civil. En materia de estado civil, de orden público, no es posible que las declaraciones de voluntad, tanto si son expresadas en un expediente matrimonial, como en un expediente de reconocimiento de paternidad o de opción de nacionalidad, puedan ser revocadas por la sola voluntad en sentido contrario de quién estimó su declaración de forma solemne, principio que es de plena aplicación en los procesos de separación y divorcio consensuados». 
La ausencia de ratificación, por parte de ambos cónyuges, conlleva la inmediata culminación del proceso en curso, ya sea debido al voluntario abandono del proceso consensual como consecuencia del libre mantenimiento del matrimonio, ya lo sea a la existencia de un conflicto latente entre las partes que origine un ulterior proceso contencioso. Pero lo cierto es que la ratificación, efectuada por ambos cónyuges, constituye un presupuesto imprescindible para la prosecución del proceso consensual.

La ausencia de cosa juzgada material predicable de la resolución que pone término al proceso consensual, como consecuencia de una ausencia de ratificación de los cónyuges, permitirá no sólo que dichos cónyuges puedan instar en el futuro un proceso de separación y divorcio contencioso, sino también, como no podría ser de otra manera, que opten por iniciar un segundo o ulterior proceso de separación o divorcio consensual idéntico, similar o ampliamente modificado, en las concretas medidas contenidas en el convenio, al que, por las razones que fueren, resultó frustrado en un momento anterior.

\section{PRÁCTICA DE LA PRUEBA Y EVENTUAL INTERVENCIÓN DEL MINISTERIO FISCAL}

Ratificada por ambos cónyuges la solicitud, si la documentación aportada fuera insuficiente, el tribunal concederá mediante providencia a los solicitantes un plazo de diez días para que la completen. Durante este plazo se practicará, en su caso, la prueba que los cónyuges hubieren propuesto y las demás que el tribunal considere necesaria para acreditar la concurrencia de las circunstancias en cada caso exigidas por el Código Civil y para apreciar la procedencia de aprobar la propuesta de convenio regulador (ex. art. 777.4 ${ }^{\circ}$ LEC).

La labor del Juez, en este peculiar período probatorio - no se olvide que la prueba tan sólo se practica, con carácter general, cuando existe desavenencia en relación con los hechos, toda vez que la aplicación del Derecho corresponde al Juez, en virtud de principios tales como iura novit curia o da mihi factum, dabo tibi ius - habrá de limitarse, en el momento actual, ante la evidenciable ausencia de «causas» legales de separación y divorcio, a verificar que los acuerdos de los cónyuges, adoptados para regular las consecuencias de la separación o el divorcio, no son dañosos para los hijos, ni gravemente perjudiciales para uno de los cónyuges.

En este momento, conviene nuevamente precisar que en materia de prueba han de regir los principios propios que configuran las di- 
versidad de peticiones y pretensiones acumuladas, de manera necesaria, en el objeto de los procesos matrimoniales.

Así, las peticiones consensuales de separación y divorcio, dónde se ha conferido un valor superior a la libre voluntad de las partes, no precisarán prueba alguna, más allá de las meras certificaciones registrales acreditativas del exigible transcurso del plazo de tres meses desde la celebración del matrimonio.

Las pretensiones sobre bienes o intereses patrimoniales, derivadas de las rupturas conyugales, en relación con las cuales ambos cónyuges muestren su conformidad, avenencia o consenso tampoco requerirán, debido a su naturaleza dispositiva, proposición ni práctica de prueba alguna. Si existiese discrepancia, entre las partes procesales, en relación con estas pretensiones sobre bienes económicos de carácter plenamente dispositivo, entonces, lógicamente, habrían de ser objeto de prueba, si bien, en tal caso, no estaríamos, en puridad, ante un procedimiento que debiera tramitarse por la vía consensual y, en consecuencia, lo conveniente sería derivarlo hacia el contencioso correspondiente.

Las pretensiones que afecten a los intereses de los hijos menores o incapaces en los procesos matrimoniales están sustraídas al poder de disposición de los cónyuges y, en tal sentido, la exteriorización de una voluntad común de aceptación de las medidas personales integradas por aquellas propuestas, no eximirá, a las partes, cuando el Juez lo estime conveniente, de practicar las pruebas que resulten oportunas, pertinentes y útiles.

La Ley no prevé la posibilidad de que el Ministerio Fiscal solicite la práctica de la prueba en este tipo de procesos matrimoniales, exclusión ésta que ha sido calificada, por la propia Judicatura ${ }^{26}$, con todo acierto, como un error, habida cuenta de la conveniencia de que sea precisamente el público defensor de los intereses de las personas especialmente vulnerables por razón de su minoría de edad o incapacidad, quién proponga la prueba que, en relación con ellas, deba practicarse.

${ }^{26}$ Vid., en este sentido, FLORS MATÍES, J., cuando afirma que «si el Ministerio Fiscal debe intervenir cuando lo que sea objeto del procedimiento afecte a intereses públicos y esa actuación lo es como representante de los intereses del menor o incapaz y en defensa de los mismos, es evidente que su posición procesal es algo más que la de un mero dictaminador o informante, de ahí que debiera haberse reconocido al Ministerio público la posibilidad de proponer prueba, en lugar de atribuir esa función al órgano jurisdiccional, al que, en esencia, no le corresponde», en El actual procedimiento consensual para la separación y el divorcio, en Separación y divorcio tras la Ley 15/2005, pp. 532 y 533 . 
El precepto $777.5^{\circ}$ de la LEC, conforme a la nueva redacción otorgada por la Ley 15/2005, dispone que «si hubiere hijos menores o incapacitados, el Tribunal recabará informe del Ministerio Fiscal sobre los términos del convenio relativos a los hijos y oirá a los menores si tuvieren suficiente juicio cuando se estime necesario de oficio o a petición del Fiscal, partes y miembros del Equipo Técnico Judicial o del propio menor. Estas actuaciones se practicarán durante el plazo a que se refiere el apartado anterior o, si éste no se hubiera abierto, en el plazo de cinco días».

La novedad del precepto, incorporada por la Ley $5 / 2005$, se refiere a la «discrecionalidad judicial» a la hora de decretar la conveniencia o inoportunidad de oír los hijos. Este trámite era obligatorio bajo la vigencia de la redacción anterior.

La supresión de esta preceptiva audiencia responde a sólidas razones de utilidad empírica y conveniencia práctica. En este sentido, resulta evidente que una excesiva intromisión, a lo largo de la tramitación de un proceso consensual, en la vida privada de las personas, no ofrece mayores ventajas, a la hora de ventilar las pretensiones voluntarias de separación o divorcio y sí puede, sin embargo, desencadenar dudas, incertidumbres o disputas ahí dónde no habían surgido.

La audiencia de los menores dependerá, pues, afortunadamente, del libre arbitrio del Juez, que ponderará, a buen seguro, en cada caso, la necesidad de oír al menor cuando hubiere indicios de alcanzar, en otro caso, una resolución desfavorable a sus necesidades e intereses reales.

Desde amplios sectores de la doctrina se ha manifestado la inconveniencia de la práctica de la audiencia de los menores en los procesos voluntarios ${ }^{27}$, tanto antes, como después de la reforma, si bien el Legislador ha optado por mantener dicha práctica, condicionada al libre arbitrio del Juez, conforme a su sano juicio, ante la posibilidad, evidenciada por la jurisprudencia, de existencia de casos en los que, bajo la apariencia de un mutuo acuerdo, subyacen, en verdad, situaciones de violencia, conflictividad emocional, dependencia económica y otras circunstancias que pueden determinar un régimen de guardia y custodia y de visitas, no movido por el interés del menor, sino por otras razones.

27 ZARRALUQUI SÁNCHEZ-EZNARRIAGA, L., Las reformas legales que nos esperan, en «Actualización del Derecho de familia y sucesiones», Asociación española de Derecho de Familia, Madrid, 2005, pp. 57 a 59. 
El criterio discrecional del Juez a la hora de considerar la «conveniencia», «oportunidad» o «necesidad», de la audiencia de los menores impone la realización de una doble inspección, supervisión o control, así, en primer lugar, la atinente a la verificación de la suficiencia del juicio que quepa atribuir al menor, e inmediatamente después, la propia audiencia.

Para un estudio a propósito de las formalidades y contenido que deba revestir esta audiencia, nos remitimos a lo dispuesto en el capítulo precedente a este, destinado al proceso matrimonial contencioso, si bien no hemos de concluir ahora sin matizar que la opinión, argumentación o posición, de estos menores, no tendrá más utilidad y efectividad que la de clarificar, atestiguar o cuestionar, ante el juez, la conveniencia o inoportunidad de los efectos personales y patrimoniales, concretamente propuestos en el convenio, que les afecten de manera directa, al efecto de su aprobación total o parcial, así como, en su caso, de su desaprobación global. Pero lógicamente las particulares manifestaciones que estos menores puedan verbalizar respecto de la crisis conyugal en la audiencia, obsta matizar, no influirán en la pretensión consensual principal de separación o divorcio, que habrá de ser decretada en todo caso ante la voluntad inequívoca, persistente y constante, en el presente proceso, de ambos cónyuges.

De la omisión de referencia legal a los incapacitados, se desprende, por lo demás, la ausencia de la práctica de la audiencia de estas personas, particularmente vulnerables, si bien dicha audiencia se practicará en todo caso, como parece razonable, cuando el Juez, de oficio, estime su conveniencia en orden al esclarecimiento de concretos extremos del convenio o así lo soliciten el Ministerio Fiscal, los progenitores o, el propio incapaz.

\section{SENTENCIA}

Cumplido lo dispuesto en los apartados anteriores o, si no fuere necesario, inmediatamente después de la ratificación de los cónyuges, el tribunal dictará la sentencia concediendo o denegando la separación o el divorcio y pronunciándose, en su caso, sobre el convenio regulador (ex. art. 777.6 LEC).

De la admisión de la pretensión principal, que lo es la de la separación o el divorcio, dependerá, como es obvio, la admisión o denegación de la pretensión subsidiaria, que lo es la relativa al convenio regulador, si bien la apreciación legal relativa a la eventual concesión o denegación de la separación o divorcio no cabe, en el momento ac- 
tual, en el que, debido a la primacía legalmente otorgada a la voluntad de las partes, el Juez no puede denegar, por razones o motivos materiales, aquella pretensión.

Así, pues, la única posibilidad de negativa a la petición de separación o divorcio vendría determinada por su inadmisión — que no denegación- por razones o motivos meramente formales.

La dicción del referido precepto de la LEC es defectuosa - dónde dice «concediendo o denegando» debiera rezar «admitiendo o inadmitiendo»- debido a que la redacción fue elaborada en el marco de un proceso de separación y divorcio causal, debiendo ahora regular el procedimiento de un proceso de separación y divorcio no causal.

Así, pues, una vez admitida la separación y divorcio - por concurrir, en efecto, todos los presupuestos procesales, incluido el plazo de 3 meses desde la celebración del matrimonio- el Juez procederá, ahora sí por motivos de fondo, a aprobar —en todo o en parte- o, en su caso, a denegar el convenio regulador.

La sentencia habrá de contener, al fin, la totalidad de extremos alcanzados en el convenio, con su debida motivación, sin que resulte posible una mera mención, remisión o referencia al mismo.

Concedida la separación o el divorcio, si la sentencia no aprobase en todo o en parte el convenio regulador propuesto, se concederá a las partes un plazo de diez días para promover nuevo convenio, limitado, en su caso, a los puntos que no hayan sido aprobados por el Tribunal. Presentada la propuesta o transcurrido el plazo concedido sin hacerlo, el Tribunal dictará auto dentro del tercer día, resolviendo lo procedente (ex. art. $777.7^{\circ} \mathrm{LEC}$ ).

Lógicamente el auto dictado por el Juez no habrá de hallarse integrado ahora, como tampoco entonces, por el exacto contenido de la propuesta de las partes, sino por lo que él mismo, a la vista de la documentación aportada, considere conveniente.

Conviene, finalmente, destacar que las trabas, dificultades u obstáculos, eventualmente impuestos a los cónyuges, tanto por parte de los Jueces, en una interpretación rígida de la legislación normativa matrimonial - de cuestionable constitucionalidad-como por parte de los Abogados, en su labor de asesoramiento técnico y, desde luego, por la de los demás profesionales del Derecho que vengan obligados a actuar en el proceso, tan sólo pueden desprenderse consecuencias negativas puesto que tal y como ha advertido la doctrina ${ }^{28}$, constituye

${ }^{28}$ MUÑOZ SABATÉ, L., El proceso matrimonial, Ed. Bosch, Barcelona, 1981, p. 13. 
una auténtica obligación, para estos profesionales, la de ayudar a los cónyuges, a desunirse, con el mínimo de traumatismos y frustraciones que pudieran traer como secuelas la agresividad, el resentimiento o, incluso, la desintegración de su personalidad.

La naturaleza voluntaria, armoniosa o pacífica de los procesos matrimoniales consensuales no comporta, de manera automática, el efectivo cumplimiento del contenido dispositivo de los pronunciamientos de condena por parte de quiénes se vieren obligados, tras la sentencia, a la realización de concretas prestaciones ${ }^{29}$, de dónde se infiere que el régimen de ejecución previsto en la LEC con carácter general, así como las particularidades, especificadas en materia matrimonial, serán de aplicación en estos procesos no contenciosos.

\section{RECURSOS}

La sentencia que deniegue la separación o el divorcio y el auto que acuerde alguna medida que se aparte de los términos del convenio propuesto por los cónyuges podrán ser recurridos en apelación. El recurso contra el auto que decida sobre las medidas no suspenderá la eficacia de éstas, ni afectará a la firmeza de la sentencia relativa a la separación o el divorcio (ex. art. 777.8 .I LEC).

En el momento actual, no cabe la denegación, por razones materiales, de la separación o el divorcio, de suerte que dicho precepto habrá de entenderlo referido a los extremos procesales de inadmisión de dichas pretensiones o, en su caso, a los materiales de denegación de las pretensiones referidas a medidas personales o patrimoniales distintas de la separación y el divorcio.

La sentencia o el auto que aprueben en su totalidad la propuesta de convenio sólo podrán ser recurridos, en interés de los hijos menores o incapacitados, por el Ministerio Fiscal (ex. art. 777.8 ${ }^{\circ}$.II LEC).

El presupuesto o requisito esencial para gozar del derecho al recurso no es otro que el gravamen o perjuicio supuesto por la resolu-

29 Vid., SERRANO CASTRO, F., cuando exclama, con rotundidad, lo siguiente: «i Cuántas veces hemos visto procedimientos de mutuo acuerdo en el que los cónyuges han firmado pacífica y cordialmente las cláusulas de un convenio regulador equitativo y pormenorizado, y que después, tras el incumplimiento de lo estipulado, ha generado incidentes de ejecución que han hecho necesario abrir varios tomos de papeles!», en Especialidades de la ejecución en la nueva LEC en relación a los procesos de familia, en «Cuestiones de familia en la nueva Ley de Enjuiciamiento Civil», Consejo General del Poder Judicial, Madrid, 2001, p. 270. 
ción que se trata de impugnar. En el caso de que el Juez apruebe, en su totalidad, una propuesta de convenio, efectuada, de común acuerdo, por ambos cónyuges, entonces resulta evidente la ausencia de gravamen, desventaja o perjuicio para ellos, razón por la que la Ley omite toda referencia a su posible ejercicio del derecho a la tutela judicial efectiva, en su manifestación del derecho a los recursos.

La modificación del convenio regulador o de las medidas acordadas por el tribunal en los procedimientos a que se refiere este artículo se sustanciarán conforme a lo dispuesto en el mismo cuando se solicite por ambos cónyuges de común acuerdo o por uno con el consentimiento del otro y con propuesta de nuevo convenio regulador. En otro caso, se estará a lo dispuesto en el artículo 775 (ex. art. $777.9^{\circ}$ LEC).

Naturalmente, la solicitud consensuada de modificación del convenio o de las medidas definitivas adoptadas en el procedimiento consensual, que se efectuará, de nuevo, por los trámites de este singular proceso amistoso, habrá de fundarse en la disconformidad, de ambos cónyuges, con la decisión judicial.

La solicitud contenciosa de aquella modificación, que habrá de sustanciarse, como es lógico, por el cauce del proceso contradictorio, habrá de fundarse, sin embargo, tal y como se ha advertido ${ }^{30}$, en la variación sustancial de las circunstancias concurrentes al momento de su aprobación.

\section{BIBLIOGRAFÍA}

ASENCIO MELLADO, J. M., «Los procesos matrimoniales», en «Proceso Civil Práctico», Tomo IX-1, dirigido por GIMENO SENDRA, V., Ed. La Ley, Madrid, 2009.

CALAZA LÓPEZ, S., La justificación de los plazos procesales en las causas de divorcio, Iuris n. ${ }^{\circ}$ 82, Madrid, abril, 2004.

ENTRENA KLERR, C., Matrimonio, separación y divorcio, Ed. Aranzadi, Pamplona, 1982.

FERNÁNDEZ DE BUJÁN, A.:

- A propósito de la competencia en materia de iurisdictio voluntaria en Derecho Romano, Revista de Derecho Notarial y A.A.M.N., T. XXVIII.

$30 \mathrm{Vid}$, en este sentido, VECINA CIFUENTES, J., Los procesos matrimoniales en la nueva Ley de Enjuiciamiento Civil, Aranzadi, BIB 2000/1956, p. 12. 
- Diferencias entre los actos de iurisdictio contenciosa y iurisdictio voluntaria en Derecho Romano, Estudios Homenaje a A. D`ors, vol. I, Pamplona, 1987.

- Consideraciones acerca del carácter clásico y jurisdiccional de la denominada por Marciano "Iurisdictio voluntaria, en D. 1.16.2. pr.», Estudios homenaje a J. Iglesias, Madrid, 1987; «Jurisdicción voluntaria en Derecho Romano», Madrid, 3. ${ }^{\text {a }}$ ed., 1999.

- La jurisdicción voluntaria en la encrucijada: su conexión con el nuevo modelo procesal de la LEC del año 2000, Revista de Derecho y opinión, Córdoba, 2000.

— «Jurisdicción Voluntaria», Ed. Civitas, Madrid, 2001.

- Los principios informadores de la jurisdicción voluntaria: una propuesta de futuro, Anuario de Derecho de la U.A.M., vol. 5, 2001.

- «Consideraciones de lege ferenda en materia de jurisdicción voluntaria y Anteproyecto de Jurisdicción Voluntaria», Revista del Colegio de Abogados de Lugo, 2001 y 2002.

- Jurisdicción Voluntaria: naturaleza jurídica y diferencias de procedimiento con la jurisdicción contenciosa, Actualidad Civil, n. ${ }^{\circ} 36$, 2001 y n. $^{\circ} 37$.

- La jurisdicción voluntaria: racionalización y redistribución de competencias, Libro Homenaje a Sánchez Mera, Madrid, 2002.

- La Jurisdicción Voluntaria: una reforma legislativa pendiente, Estudios Jurídicos. Ministerio de Justicia, vol. IV, 2002.; Noción de iurisdictio y etapas. Jurisdicción contenciosa y jurisdicción voluntaria, Portal electrónico de Derecho, IUSTEL, 2002.

- La reforma legislativa de la jurisdicción voluntaria: reflexiones de presente y perspectivas de futuro, n. ${ }^{\circ} 163,2004$.; Jurisdicción Voluntaria: Historia (I), Problemas (II), Interrogantes (III) y Soluciones (IV), Tribuna Pública, Mercados, Voz de Galicia, 12-9, 19-9, 26-9 y 3-10-2004.

- La reforma de la Jurisdicción Voluntaria: problemas, interrogantes, soluciones, Diario «La Ley» de 23 de marzo de 2005.

- El nuevo perfil de la Jurisdicción voluntaria en el Anteproyecto de Ley de octubre de 2005 (de tutela de relaciones jurídicas privadas a la protección de intereses generales, públicos o sociales), Diario La Ley de 8 de junio de 2006.

- La Jurisdicción Voluntaria. El Anteproyecto de junio de 2006, en El Notario del siglo XXI, agosto de 2006; «Observaciones al Proyecto 
de Ley de Jurisdicción Voluntaria, de octubre de 2006 (I)», Diario La Ley de 27 de noviembre de 2006.

- Observaciones al Proyecto de Ley de Jurisdicción Voluntaria, de octubre de 2006 (y II), Diario La Ley de 28 de noviembre de 2006.; El Notario como órgano de la Jurisdicción Voluntaria en el Proyecto de Ley de 20 de octubre de 2006, en El Notario del siglo XXI, 2006.

- La nueva configuración de la Jurisdicción Voluntaria en el Anteproyecto de Ley de junio de 2006, en «Otrosí. Revista del Colegio de Abogados de Madrid», n. ${ }^{\circ}$ 80, 2006.

- El Proyecto de Ley de Jurisdicción Voluntaria, en Economist\&Jurist n. ${ }^{\circ} 106$ y 107, 2007.

- La protección jurídica patrimonial de las personas con discapacidad, en libro compartido, dirección y coordinación Prof. I. Serrano, Ed. Tirant lo Blanch, Valencia, 2007.

- La Jurisdicción Voluntaria en el marco del Estado constitucional de Derecho, en Anales de la Academia Matritense del Notariado, 2007.

- La Jurisdicción Voluntaria en las Cortes Generales, Diario La Ley de 16 de octubre de 2007.

- Hacia una teoría general de la Jurisdicción Voluntaria, volumen I, Ed. IUSTEL, Madrid, 2007.

- Hacia una teoría general de la Jurisdicción Voluntaria, volumen II, Ed. IUSTEL, Madrid, 2008.

FLORS MATÍES, J.:

- El actual procedimiento consensual para la separación y el divorcio, en Separación y divorcio tras la Ley 15/2005.

- Procedimiento, en Separación y divorcio tras la Ley 15/2005, VV.AA. (MONTERO AROCA, J.; FLORS MATÍES, J., ARENAS GARCÍA, R.), Ed. Tirant lo blanch, Valencia, 2006.

GIMENO SENDRA, V.:

- El derecho a un proceso sin dilaciones indebidas, Jornadas sobre Derechos Humanos, Poder Judicial, número especial, CGPJ, Madrid, 1986.

- Introducción al Derecho Procesal, Ed. Colex, 2. ${ }^{\mathrm{a}}$ ed., Madrid, 2007.

- Derecho Procesal Civil. I. El proceso de declaración. Parte general, Ed. Colex, 2. ${ }^{\text {a }}$ ed., Madrid, 2008.

- Derecho Procesal Civil, II, Los procesos especiales. Parte especial, Ed. Colex, 2. ${ }^{a}$ ed., Madrid, 2008. 
- Comentario a los artículos 19 a 22 de la Ley de Enjuiciamiento Civil, en "Proceso Civil Práctico», Tomo I, de VV.AA, dirigido por GIMENO SENDRA, V., Ed. La Ley, Madrid, 2009.

GONZÁLEZ DEL POZO, J. P., Los procedimientos consensuales, en VV.AA. (GONZÁLEZ DEL POZO, J. P., PLANES MORENO, M. D. y SANTANA PÁEZ, E.), Los procesos de familia: una visión judicial. Compendio práctico de doctrina y jurisprudencia sobre los procesos de familia y menores, coordinados por HIJAS FERNÁNDEZ, E., Ed. Colex, Madrid, 2007.

IHERING, R., La lucha por el Derecho, Ed. Termis, Colombia, 2000.

LASARTE, C., Principios de Derecho Civil VI, Derecho de familia, Ed. Marcial Pons, 5. ${ }^{\mathrm{a}}$ ed., Madrid, 2006.

MONTERO AROCA, J., La modificación de los procesos matrimoniales, en Separación y divorcio tras la Ley 15/2005, VV.AA. (MONTERO AROCA, J.; FLORS MATÍES, J., ARENAS GARCÍA, R.), Ed. Tirant lo blanch, Valencia, 2006.

MORENO CATENA, V., Derecho Procesal Civil, parte especial, Ed. Colex, 3. ${ }^{a}$ ed., Madrid, 2003.

MUÑOZ SABATÉ, L., El proceso matrimonial, Ed. Bosch, Barcelona, 1981.

PASTOR VITA, F. J., Una primera aproximación al Proyecto de Ley de reforma del Código Civil en materia de separación y divorcio, Diario La Ley n. ${ }^{\circ}$ 6235, 20 de abril de 2005.

PÉREZ GORDO, A., Los juicios matrimoniales (nulidad, separación y divorcio), Bosch, Barcelona, 1982.

SERRANO CASTRO, F., Especialidades de la ejecución en la nueva $L E C$ en relación a los procesos de familia, en «Cuestiones de familia en la nueva Ley de Enjuiciamiento Civil», Consejo General del Poder Judicial, Madrid, 2001.

VECINA CIFUENTES, J., Los procesos matrimoniales en la nueva Ley de Enjuiciamiento Civil, Aranzadi, BIB 2000/1956.

VILALTA, A. E. y MÉNDEZ, R. M., Divorcio contencioso, Ed. Bosch, Barcelona, 1998.

ZARRALUQUI SÁNCHEZ-EZNARRIAGA, L., Las reformas legales que nos esperan, en «Actualización del Derecho de familia y sucesiones», Asociación española de Derecho de Familia, Madrid, 2005. 